\title{
Reform and Practice of Practical Teaching Curriculum system of Electronic and Information Engineering
}

\author{
Yu Tang ${ }^{1, a}$, Gang $\mathrm{Wu}^{2, \mathrm{~b}}$ \\ ${ }^{1}$ College of Telegraph, Pan Zhihua University, 617000, China \\ ${ }^{2}$ College of Telegraph, Pan Zhihua University, 617000, China \\ aemail:wgdd2009@126.com, bemail:wugang_d@126.com
}

Keywords: Electronic and Information Engineering; Practical Teaching; Reform and Practice

\begin{abstract}
Based on the training-goal of the Information and Electronic Science required by Steering Committee of Ministry of Education toward the Electronic and Information Engineering, the paper, which combined with the existing problems in the practical teaching of Electronic and Information Engineering, puts forward the content of the practical teaching course system innovation. ,which adheres to the teaching idea of regarding ability training as the main line, and the "electronic system" establishment as the starting point, and classifying the practical teaching system into six parts, namely, basic experience, analysis and design, comprehensive application and development, innovation of science and technology, practical ability training, and practical teaching evaluation to structure a diversified practical teaching model with the combination of teaching and studying, curricular and extracurricular, theory and practice, actual and virtual, the campus and off-campus teaching.
\end{abstract}

\section{Introduction}

Students of electronic and information engineering should have four knowledge According to the Guiding Committee of information science and Electronics of the Ministry of education: (1) circuit and electronic; (2) electromagnetism; (3) information processing; (4) computer. Four skills are: (1) the installation, debugging and application of electronic circuit, and the application of electronic measurement technology and circuit testing ability; (2) the integrated use of knowledge in circuit design and experiment ability, (3) the use of CAD system environment analysis and design ability; (4) the ability of using the virtual instrument [1].

Based on the requirement of the training objectives of electronic and information engineering in the construction of practical teaching system, should change the traditional experimental teaching mode, integration and optimization of experimental content, build the practice teaching system of the ability training as the main line, hierarchical join each other, more modules [2], the purpose is to strengthen the students' practical ability and innovation consciousness, highlight the characteristics of electronic information engineering specialty. Achieve the training goal of "thick foundation, wide caliber, strong ability, high quality" [3].

\section{Problems Existing in the Practice Course System of Electronic Information Engineering}

Practice teaching is very important part of electronic information engineering, after nearly 10 years of efforts, course system construction of the practice teaching of electronic information engineering has made certain progress, but there is still a big gap with the training requirements of professional skills of the ministry of education, mainly embodied in the following aspects:

\section{The Practice Teaching Goal.}

Practice teaching of electronic information engineering is not clear, teaching system to be perfect, positioning requirements of "should know" and "should be ability" need to be further clear, the training of the students' comprehensive abilities of design and engineering practice need further attention, the students' engineering quality and practice ability training methods need into a improvement. 


\section{The Practice Teaching Content Settings.}

At present, electronic information engineering mostly used the traditional training mode in the practice teaching content, namely the installation, commissioning of electronic circuits and electronic measurement, etc., do not reflect the problems of the actual engineering design , the direction of the modern electronic information technology development is not fully reflected, heavy theory, light practice, experiment course is still attached to the theoretical courses, class is less, some teaching practice become a mere formality, and the basis of practice, professional experiment, curriculum design, professional and comprehensive training content such as contact the graduation design is not tight, not the concept of "electronic system".

\section{The Practice Teaching Team Construction.}

The second classroom teaching practice guidance team of electronic information engineering did not establish, in the aspect of professional ability training of the second classroom lack of effective methods and means of correctly, the cultivation of the students' comprehensive development ability and innovative ability lacks the corresponding environment and conditions, such as the team's activities and the content of the activities, etc. [4]. The so-called "open laboratory" is just a form.

\section{The Practice Teaching Evaluation System.}

The evaluation system of practice teaching of electronic information engineering still continue to use the traditional method, the experiment course of practice teaching, teaching practice, production practice, graduation thesis, social practice and productive labor and so on, there is no clear evaluation system and evaluation methods, the practice teaching quality supervision and inspection is not enough, Weak links of practice teaching content, methods, attitudes and effect have no further rectification

\section{Reform and Practice of Practical Teaching Curriculum System of Electronic and Information Engineering}

\section{Architecture of practice teaching course system.}

Electronic information engineering practice teaching course system is based on practical ability and innovation ability as training goal, therefore, , it's going to fully embody the practical teaching plays in the process of practice teaching training plan, to achieve imparting knowledge, cultivating ability, improve the coordinated development of various quality in the process of the implementation of practical courses, also pay attention to students' exploration spirit, scientific thinking ability, innovation ability and practice, and sets up concept of overall coordination of the theoretical teaching and experimental teaching, fundamentally change the traditional practice teaching mode. The talents training goal of practice teaching based on the above requirements, the design of architecture of practice teaching course system is shown in figure 1 [5].

\section{Basic Experiment Course System.}

Based practice teaching course system is the basis of the practice teaching of electronic information engineering, it's biggest and most widely, the most effective, it includes components of recognition and measurement, assembly and debugging of the circuit, the use of instruments and meters, the purpose is to cultivate students basic operating skills, scientific experiment method, serious working attitude, deepen students' understanding of basic specialized knowledge, stimulate students' interest in professional. It includes "analog electronic technology experiment", "circuit principle experiment", "digital electronic technology experiment", "high frequency electronic circuit experiment", "theory of electromagnetic field experiment", "microwave technology and antennas experiment", "the FPGA/CPLD experiment", "VHDL and EDA technology experiment", "sensing technology experiment", "the principle and application of single-chip microcomputer experiment", "digital signal processing experiment", "signals and systems experiment", "communication principle", "DSP application technology experiment". it is divided into basic experiment, comprehensive experiment and computer programming, simulation and so on three levels in the practice teaching form [6]. 


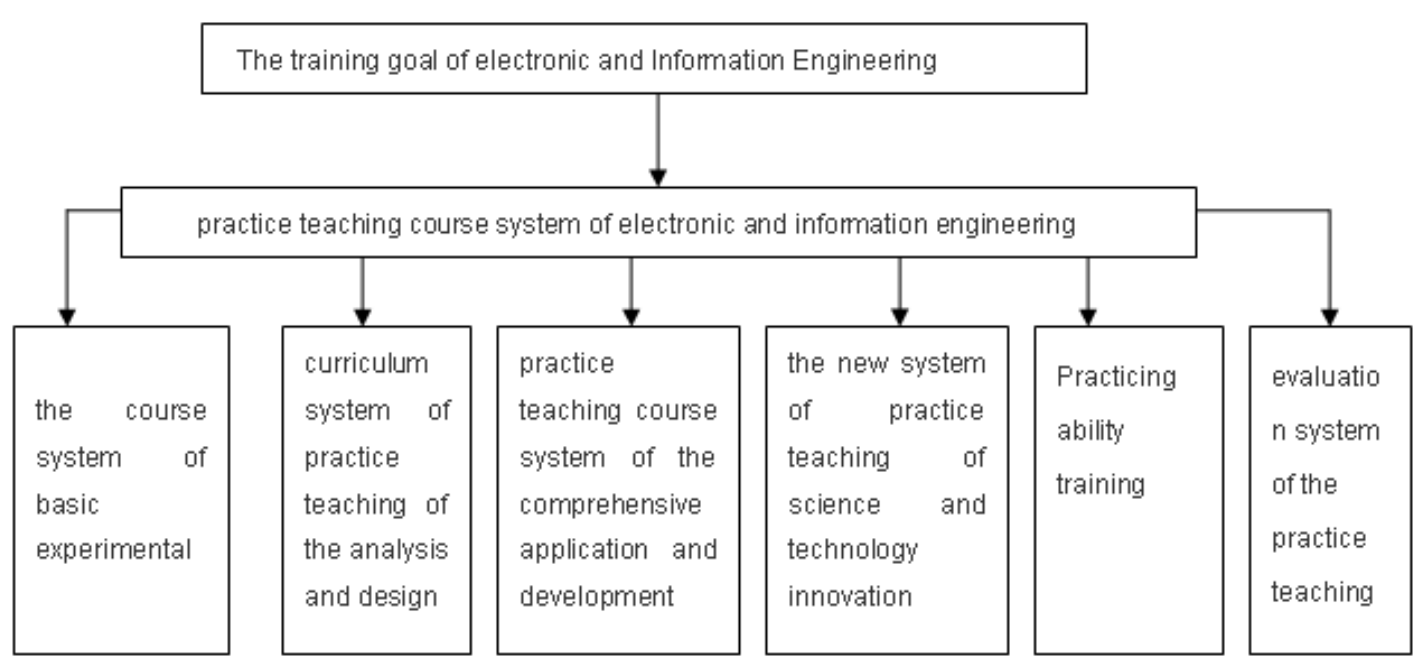

Fig.1. Architecture diagram of course system of practice teaching

\section{Practice Teaching Course System of Analysis and design.}

The goal of analysis and design practice teaching course system is to apply what they have learned basic theoretical knowledge and basic skills, in under the guidance of teachers, analysis the characteristics and function of "small circuit system", in accordance with the requirements of circuit design, using computer simulation technology independently complete the design of the "small circuit system" ,to achieve the cultivation of the students abilities of preliminary design and engineering practice, it is mainly comprehensive application of "analog electronic technology", "digital electronic technology", "high frequency electronic circuit", "single-chip computer application technology", "application of DSP technology", "circuit principle", "electronic circuit CAD" and so on.

The Curriculum System of Comprehensive Application and Development of Practice Teaching.

The curriculum system of comprehensive application and development of curriculum practice teaching is to cultivate the students to apply the knowledge to complete the design and development of "electronic system" comprehensive, so that the design of the "system" is close to the actual project, with the ability to design and develop strong comprehensive application of "electronic system", and would "analysis and design practice" the content of sublimation.

\section{1) Design of MCU Application System}

Single chip microcomputer application system design is conducted at the end of the sixth semester, for 2 weeks. The ask students to design a "integrated control circuit system" according to the actual needs, the concrete content includes "design of the software and hardware design of circuit system", realize the comprehensive training of students of the single chip microcomputer system hardware circuit and software programming, also according to the graduation design implementation, and asks the students to make a "single chip microcomputer application the prototype system", to lay the foundation for the comprehensive application and development of follow on innovations.

\section{2) Integrated Design of Information Engineering}

This design only for information engineering students, arranged at the end of the seventh semester, design for 1 weeks, the direction of the students have completed the basic courses of the specialty and the main professional course learning, in the design process, requiring students to use "data acquisition technology", "data communication and network", "digital image processing", "remote control technology" and the related circuit knowledge, to complete the design strategy design, signal acquisition, signal analysis and processing, and the realization of the use of computer technology, the purpose is to cultivate students "ability of information processing and engineering design capability of information system [8]".

3) Electronic Circuit Design and Implementation of Comprehensive Professional Design

This design only for students of professional direction of electronic circuit design and implementation, course also arranged at the end of the seventh semester, design for 1 weeks, 
students have completed the course of the specialized foundation and the professional direction, the use of "integrated circuit design", "embedded system", "design of switching power supply", "the principle of electromagnetic compatibility and design technology" and so on, to design an "electronic application system", to enable students to systematically master drawing, simulation, calculation, experiment, debugging and process of design skills in the field of electronic circuit design, purpose is to cultivate students' the ability of comprehensive design and application development [9] .

\section{A New System of Practice Teaching of Innovation of Science and Technology.}

A new system of practice teaching of innovation of science and technology is at the top of the practical teaching system. The purpose of teaching is to cultivate students with strong thinking ability, innovation ability, practical ability, and good engineering quality and so on, the specific method is to adhere to the unity of the curricular and extracurricular, give full play to the role of second classroom, strengthen the construction of the practice base outside the school, through various forms of training for the students' innovation consciousness and ability to provide better platform.

\section{1) Increase the Intensity of the Open Laboratory}

Students of electrical and information engineering college after school, each student is issued a "development board" (according to their own needs, to "MCU development board", "the ARM development board ", "FPGA development board" choose one), take the guidance system and take the new method with the old, make full use of the second class, with "development board" as the core, carries on the design to the hardware and software of "electronic system", but also increase the openness of the laboratory, continuously improve "design laboratory" of electronic innovation, provide strong support for the students' innovation practice activity, but also to provide better learning environment of design and research to excellent students.

2) The Organization of Various Extracurricular Activities of Science and Technology

At present, with the rapid development of information technology, gradually prosperous science and technology competition activities of domestic college students, provides more opportunities for students to practice innovation of science and technology, Such as domestic "National Undergraduate Electronic Design Contest", the national "Challenge Cup" competition of science and technology, international "robot" World Cup (ROBOCUP), international students "program design" contest (ACM), fierce competition of the science and technology more, Although the students enthusiasm is very high, but it is often difficult in the implementation process, many students give up halfway, in order to solve this problem, extracurricular activities of science and technology must be targeted, Such as low grade students should take "science education" mainly, they often organized to listen to "academic report" and "popular science lectures", Such as low grade students should take "science education" mainly, they often organized to listen to "academic report" and "popular science lectures", and guide them to carry "electronic system design of simple"; As for the high grade students with professional basic theory and professional skills, they should take all kinds of science and technology competition and innovation activities, to guide them to use scientific methods to explore new knowledge, solve new problem.

\section{3) Strengthening the Construction of Science and Technology Innovation Team}

The construction of science and technology innovation team is an important and effective way to implement quality education and improve the college students' practice ability, also it plays an important role in the promotion of students, expand employment, guiding the students to adapt the society. Therefore, strengthening the construction of science and technology innovation team, and scientific management, the guidance of professional, make it become an important guarantee of cultivating students' innovation ability.

\section{Practicing Ability Training.}

The training goal of electronic information engineering is "thick foundation, wide caliber, strong ability, high quality" based on the practice teaching, the curriculum was added in the "executive ability training" module, the main contents are: " training of electrician skill ", " training of electronic repair technology skills ", " training of appliance repair technology skills ", "the 
construction of electrical cost of teacher training" in the content, In this process, the requirements of the students choose a training project according to their characteristics and preferences, and put into practice, the process is arranged in the sixth semester, its main purpose is to make the students obtain training of the system to engineering design capability and engineering practice ability [11].

\section{Establishing Scientific Evaluation System of Practice Teaching.}

Establishing scientific evaluation system of practice teaching is to the supervise and inspection of practice teaching quality, it is quality guarantee of the practice teaching, achieve the improvement of weak links of teaching practice based on the results of quality evaluation, the purpose is further improve quality of practice teaching, generally speaking, the practice teaching evaluation connotation is: teaching management, teaching content, teaching methods, teaching attitude, teaching effect and so on, "Syllabus" should have a clear teaching requirements and evaluation methods for the "basic practice teaching", "analysis and design of practice teaching", "the comprehensive application and development of practice teaching", "science and technology create new teaching practice", "practice ability training" and so on, so that each student to clarify evaluation standard of the practical teaching, purpose is to require students to pay attention to practice teaching, from passive learning into active participation, promoting the students' practical ability raise.

\section{Conclusion}

The cultivation and development of students' practical ability is a long-term project, content updates and system optimization as the focus based on strengthening the theory of teaching, with basic skills, comprehensive analysis, design ability, research ability, innovation spirit as the goal, to establish the concept of "electronic information engineering system" as the main line, construction practice teaching system linked with theory teaching, and strengthening digital, integrated and systematic of practice teaching, strengthening training of design and comprehensive designing, The practice of teaching content and the needs of society combination, enhance practice ability of the students' engineering; people-oriented, establish the practice teaching mode of student - centered.

\section{References}

[1] MA MingTao .On the Construction and Development of the Curriculum System of Electronic Information Science and Technology, Journal of Jilin Agricultural Science and Technology College[J] . 2009 (3) . 68-69.

[2] YAN Jin, NONG Gao-hai. On Curriculum System Reform of Electronic Information Engineering in Newly-upgraded Universities, Journal of Baise University.2009( 3).71-74

[3] Rui Ha . Study On Modern Technology of Electronic and Information Engineering [J], Information System Engineering.2003(11) 16-20.

[4] ZHOU Xian-chen, Research on Reform of Practice Teaching Mode in Electronics and Information Engineering[J], Journal of Hunan Business College. 2006(10).117-119.

[5]. Qiuhua Wang. The Explore on Curriculum Reform of Electronic Information Engineering of Our School [J]. China Science and Technology Information .2008 (8) .229 -230.

[6] Yongshun Liu, Jin Wang. Development trend of Modern electronic measuring instrument [J], Journal of Anyang Normal University.2008 (2) .56-58.

[7] Ruirui Yao, The General trend of Modern Communication Technology Development [J], Chinese High-tech Enterprises .2012 (2). 6-8.

[8] XIE Yun ,GU Ai Yu. Particular Specialty Construction of Electronic Information Science and Technology And Talent Cultivation. Journal of Guangdong University of Technology( Social Sciences Edition). 2007(9).47-49 
[9] Yan Xu, Qilong,Hou, Quan Hou . The Development and The Prospect of Modern Communication [J], Silicon Valley, 2012 (3). 97-98.

[10] Zining Yang. Development and Application of Microwave Technology [J], China Information of Science and Technology .2006 (18). 142-143.

[11]Xiaoyi Dong, Xueshen Lv. Development of Optoelectronic Devices [J], Optoelectronic Laser .1990(1). 46-50. 